\title{
Total and CO-reactive heme content of actinorhizal nodules and the roots of some non-nodulated plants
}

\author{
JOHN D. TJEPKEMA \\ Department of Botany and Plant Pathology, University of Maine, Orono, ME 04469, USA \\ and DARWIN J. ASA \\ Department of Biology, University of Michigan-Flint, Flint, MI 48502, USA
}

\author{
Key words Actinorhizae Alnus Casuarina Frankia Hemoglobin Myrica Nitrogen \\ fixation Root nodules
}

Summary The concentration of total and CO-reactive heme was measured in actinorhizal nodules from six different genera. This gave the upper limit to hemoglobin concentration in these nodules. Quantitative extraction of CO-reactive heme was achieved under anaerobic conditions in a buffer equilibrated with $\mathrm{CO}$ and containing Triton X-100. The concentration of CO-reactive heme in nodules of Casuarina and Myrica was approximately half of that found in legume nodules, whereas in Comptonia, Alnus and Ceanothus the concentrations of heme were about 10 times lower than in legume nodules. There was no detectable CO-reactive heme in Datisca nodules, but low concentrations were detected in roots of all non-nodulating plants examined, including Zea mays. Difference spectra of $\mathrm{CO}$ treated minus dithionite-reduced extracts displayed similar wavelengths of maximal and minimal light absorption for all extracts, and were consistent with those of a hemoglobin. The concentration of CO-reactive heme was not correlated to the degree to which $\mathrm{CO}$ inhibited nitrogenase activity nor was it affected by reducing the oxygen concentration in the rooting zone. However, there was a positive correlation between heme concentration and suberization or lignification of the walls of infected host cells. These observations demonstrate that, unlike legume nodules, high concentrations of heme or hemoglobin are not needed for active nitrogen fixation in most actinorhizal nodules. Nonetheless, a significant amount of $\mathrm{CO}$-reactive heme is found in the nodules of Alnus, Comptonia, and Ceanothus, and in the roots of Zea mays. The identity and function of this heme is unknown.

\section{Introduction}

Until recently, hemoglobins were not thought to occur in higher plants, except in the root nodules of legumes. However, hemoglobins have now been purified from the root nodules of two different nonlegumes, and there is spectroscopic evidence for hemoglobin in the nodules of additional nonlegumes ${ }^{3,12,26.29}$. Moreover, using cloned leghemoglobin cDNA as a probe, there is evidence for cross-hybridizing sequences in genomic DNA from a wide variety of plants, including plants that do not form root nodules ${ }^{14,20,21,23,24}$. All of the above suggests that the gene for hemoglobin is widespread in the plant kingdom. Hemoglobins have also been found in bacteria ${ }^{1,30}$.

In the present work we have measured the concentration of total heme and CO-reactive heme in selected actinorhizal root nodules and in roots 
of non-nodulating plants as a first step in investigating the function of hemoglobin in nonlegumes. Nodule properties that might be related to hemoglobin function were also studied. With a single exception, we found that soluble, CO-reactive heme was a substantial fraction of total heme in all nodules and roots investigated. However, high concentrations of heme were found in only two of the six genera of actinorhizal plants studied.

\section{Materials and methods}

\section{Plant growth}

All nodulated plants were grown on vermiculite and were watered twice weekly with a onefourth strength -N Hoagland's solution and with distilled water on other days. Between the time of seed germination and nodule development, the $-\mathrm{N}$ solution was supplemented with $1 \mathrm{~m} M$ urea. The potted plants were kept in a growth chamber at a constant temperature of $23^{\circ} \mathrm{C}$, relative humidity of $70 \%$, light intensity of 300 to $400 \mu \mathrm{mol} \mathrm{m} \mathrm{m}^{-2} \mathrm{~s}^{-2}(400-700 \mathrm{~nm})$, and photoperiod of $17 \mathrm{~h}$. Casuarina was inoculated with Frankia strain HFPCcI3 ${ }^{32}$, Alnus with strain HFPArI3 $3^{5}$, Myrica with strain LLR 161101, Datisca and Ceanothus with crushed nodules of Ceanothus americanus, and Comptonia was inoculated with crushed nodules of Comptonia that were collected in the town of Orono. The crushed nodules of Ceanothus were from plants whose original inoculum was soil and nodules from a Ceanothus site in Massachusetts. Plants were used in experiments at two to three months after inoculation. Roots of Zea mays were harvested eight days after planting the seeds in a flat of vermiculite.

\section{Acetylene reduction assays}

Nitrogenase activity was measured using the acetylene reduction assay ${ }^{8.13}$. Intact potted plants ( $7.5 \mathrm{~cm}$ diameter pots) were placed in $1000-\mathrm{ml}$ tall form beakers that were sealed with a plastic lid and modeling clay. Acetylene was added to the jars to give a mixture of $10 \%$ acetylene and $90 \%$ air. The jars were incubated at $23^{\circ} \mathrm{C}$ in the dark, and gas samples were taken at 15,30 , and $45 \mathrm{~min}$ after acetylene addition. The concentration of acetylene and ethylene was measured using a gas chromatograph equipped with a flame ionization detector. The rate of acetylene reduction was constant as a function of time.

The effect of $\mathrm{CO}$ on nitrogenase activity was measured using the acetylene reduction assay as described above. After a 60 -min acetylene reduction assay in the absence of $\mathrm{CO}, \mathrm{CO}$ was injected into the incubation jars, and the assay was continued for an additional $60 \mathrm{~min}$. In control jars to which no $\mathrm{CO}$ was added, the acetylene reduction rate was usually constant during the $2-\mathrm{h}$ assay. Inhibition by $\mathrm{CO}$ was calculated from the acetylene reduction rate for individual plants before and after the addition of $\mathrm{CO}$. If there was any change in acetylene reduction rate by the control jars during the assay, this was taken into account in the calculations.

\section{Extraction of total and CO-reactive heme}

CO-reactive heme was extracted from root nodules using a modification of the method of Appleby $^{3}$. The extraction buffer $(0.1 \mathrm{M}$ potassium phosphate, $1 \mathrm{mM}$ EDTA, $1 \%$ Triton X-100, pH 7.4) was equilibrated with $\mathrm{CO}$ before use and $5 \mathrm{ml}$ was added to between 50 and $1000 \mathrm{mg}$ of nodules placed in a $15 \mathrm{ml}$ glass centrifuge tube (Corex No. 8441). Then $10 \mathrm{mg}$ of sodium dithionite was added and the tube was sealed onto a Biospec homogenizer (No. 1281-0, 10,000 rpm; 1/2 inch stator) using a rubber stopper. The headspace was flushed with argon or nitrogen gas for $60 \mathrm{~s}$, then the homogenizer was run at room temperature for $40 \mathrm{~s}$. The tube was then removed from the homogenizer, stoppered, flushed with argon or nitrogen, and centrifuged at $4500 \mathrm{~g}$ for $30 \mathrm{~min}$ at $20^{\circ} \mathrm{C}$. The supernatant was analyzed for heme content.

Roots were extracted in the same way, except that $0.2 \mathrm{~g}$ of insoluble polyvinylpolypyrrolidone 


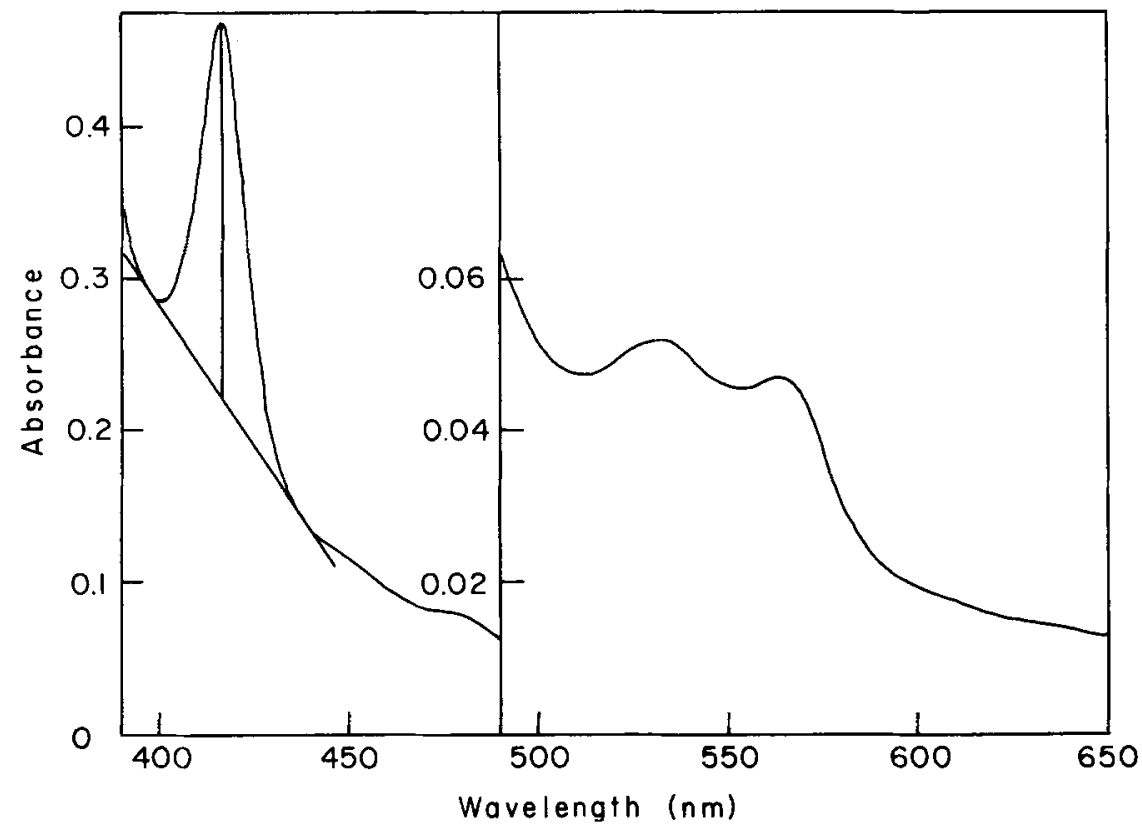

Fig. 1. Absorption spectrum of a CO-equilibrated extract from the nodules of Myrica gale. The vertical line at $416 \mathrm{~nm}$ is the value of $A$ from which the concentration of CO-reactive heme was calculated.

(Sigma No. P-6755) was added to each tube after homogenization. This reduced background absorbance in the $420 \mathrm{~nm}$ region that interfered with quantification of the CO-reactive heme.

Total heme was extracted in the same way as CO-reactive heme, except that $2 \mathrm{ml}$ of pyridine was added to the $5 \mathrm{ml}$ of homogenate immediately after the homogenization was completed. This method was derived from that of Davenport ${ }^{10}$.

\section{Spectroscopic methods}

Spectra were recorded using a Bausch and Lomb Spectronic 2000 spectrophotometer of $2 \mathrm{~nm}$ slit width, set at a $100 \mathrm{~nm} \mathrm{~min}^{-1}$ scan speed. Wavelength and absorbance accuracy were checked with neutral density and holmium oxide filters (Thomas Scientific) and agreed with the factory settings. Samples of about $1.0 \mathrm{ml}$ were measured in semi-micro cuvettes.

For difference spectra, $\mathrm{CO}$ was omitted from the extraction buffer, and extracts were added to both sample and reference cells. The sample cell was then gently bubbled with $\mathrm{CO}$.

The concentration of CO-reactive heme was calculated by drawing a "baseline" between the minima at 400 and $435-445 \mathrm{~nm}$ on either side of the Soret absorption peak as indicated in Fig. 1 . The $\Delta \mathrm{A}$ was then measured from the baseline to the absorption peak at 416 to $420 \mathrm{~nm}$. To calculate the concentration of CO-reactive heme we assumed a $\Delta \mathrm{E}(\mathrm{m} M)$ value of 180 . This value (C.A. Appleby, personal communication) was determined from pure Parasponia carboxyhemoglobin and is representative of similar hemoglobins from a variety of sources.

Total heme concentration was calculated in a manner similar to that used for CO-reactive heme. The "baseline" was drawn from the minima at about 538 and $573 \mathrm{~nm}$ on either side of the alpha peak of pyridine proto hemochrome (see Fig. 2). To calculate total heme concentration, we derived a $\Delta \mathrm{E}$ $(\mathrm{m} M)$ value of 28.7 from an enlargement of Fig. 1 of Paul et al. ${ }^{19}$.

Growth of plants at $5 \mathrm{kPaO}$

After initiation of root nodules and growth on vermiculite, seedlings $(0.5$ to $1.6 \mathrm{~g}$ fresh weight) 


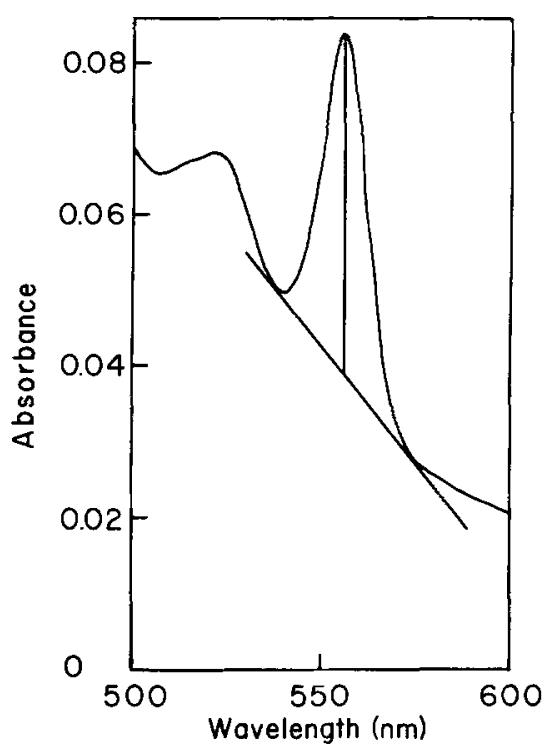

Fig. 2. Absorption spectrum of a pyridine-treated extract from nodules of $M y r i c a$ gale. The vertical line at $556 \mathrm{~nm}$ is the value of A from which the concentration of total heme was calculated.

were transferred to water cultures ( $1 / 4$ strength $-\mathrm{N}$ Hoagland's solution). Plastic containers $(20 \mathrm{~cm}$ diameter, $20 \mathrm{~cm}$ high) with snap-on lids were used, with all six plants of a given treatment being placed in the same container. The plants were sealed into split rubber stoppers by wrapping the stems with thin strips of closed cell foam. The stoppers were inserted in holes in the lid, and the cultures were continuously bubbled with either air or a mixture of $95 \% \mathrm{~N}_{2}, 5 \% \mathrm{O}_{2}$, and $0.04 \% \mathrm{CO}_{2}$. A fritted disk was used to disperse the gas and the gas exiting from the cultures bubbled with $5 \%$ $\mathrm{O}_{2}$ was collected for analysis by gas chromatography ${ }^{31}$. Both entering and exiting gas was $5.0 \% \mathrm{O}_{2}$, while entering gas was $0.041 \% \mathrm{CO}_{2}$, and exiting gas was $0.074 \% \mathrm{CO}_{2}$. The gas flow rate was $30 \mathrm{ml}$ $\mathrm{min}^{-1}$ or more. The exterior of the containers was covered with aluminum foil to prevent the growth of algae. The water level was kept high, to minimize gas leakage at the seal between the rubber stoppers and plant stems. Seedlings of Myrica gale were grown in the water cultures for 14 days, while Alnus rubra seedlings were grown for 20 days in the cultures.

Tests for suberin and lignin

Autofluorescence was observed by the method of Berg ${ }^{4}$, except that $350-500 \mathrm{~nm}$ excitation and $550 \mathrm{~nm}$ barrier filters were used. Phloroglucinol staining was as described by Berg, while chromic acid digestion was oniy 1 day instead of the 4 days used by Berg.

\section{Results and discussion}

\section{Extraction of $\mathrm{CO}$-reactive heme}

In our initial experiments ${ }^{26}$, soluble polyvinylpyrrolidone (PVP) was used instead of Triton X-100 in the extraction buffer. We discontinued use of PVP because it resulted in extracts that absorbed light more strongly at the shorter wavelengths and thus interfered with the assay for CO-reactive heme. However, both methods yielded about the same 
Table 1. Total heme, CO-reactive heme, and acetylene reduction rates in actinorhizal nodules, nodules of Lupinus, and roots of Zea mays. (Means $\pm S E, n=3$ to 6)

\begin{tabular}{|c|c|c|c|}
\hline \multirow[t]{2}{*}{ Species } & $\begin{array}{l}\text { Total } \\
\text { heme }\end{array}$ & $\begin{array}{l}\text { CO-reactive } \\
\text { heme }\end{array}$ & \multirow{2}{*}{$\begin{array}{l}\begin{array}{l}\text { Acetylene } \\
\text { reduction rate }\end{array} \\
\mu \mathrm{mol} \mathrm{h}^{-1} \mathrm{~g}^{-1} \\
\text { (fresh weight) }\end{array}$} \\
\hline & \multicolumn{2}{|c|}{$\mathrm{nmolg}^{-1}$ (fresh wt) } & \\
\hline Lupinus albus (legume) & $197 \pm 11$ & $174 \pm 0.4$ & - \\
\hline Casuarina cunninghamiana & $95.8 \pm 23$ & $80.1 \pm 4.4$ & $66.8 \pm 2.2$ \\
\hline Myrica gale & $127 \pm 11$ & $103 \pm 7$ & $43.5 \pm 4.3$ \\
\hline Comptonia peregrina & $31.5 \pm 2.2$ & $17.4 \pm 0.9$ & $16.4 \pm 0.4$ \\
\hline Alnus rubra & $23.7 \pm 1.2$ & $15.4 \pm 0.6$ & $43.1 \pm 1.5$ \\
\hline Ceanothus americanus & $15.6 \pm 2.7$ & $11.6 \pm 1.5$ & $49.0 \pm 3.2$ \\
\hline C. americanus - roots only & $4.3 \pm 0.4$ & $1.4 \pm 0.2$ & - \\
\hline Datisca glomerata & $13.0 \pm 0.6$ & 0.0 & $48.4 \pm 2.1$ \\
\hline Zea mays - roots & $4.1 \pm 0.3$ & $1.7 \pm 0.1$ & - \\
\hline
\end{tabular}

amount of CO-reactive heme: when 5\% soluble PVP (Sigma PVP-10, $10,000 \mathrm{~mol} . \mathrm{wt})$ was used the yield of CO-reactive heme from nodules of Myrica gale was $86 \pm 8 \mathrm{nmol} \mathrm{g}^{-1}$, while with $1 \%$ Triton X-100 the yield was $98 \pm 10 \mathrm{nmolg}^{-1}$ (mean $\pm \mathrm{SE}, \mathrm{n}=3$ ).

CO-reactive heme could also be extracted when Tween 80 or CHAPS (Sigma No. C 3023) were substituted for the Triton X-100. No CO-reactive heme could be extracted in the absence of soluble PVP or the detergents mentioned. The insoluble form of PVP was completely ineffective when used without soluble PVP or detergent.

These results suggest that the CO-reactive heme in actinorhizal nodules is either in an insoluble form when present in the nodule, or has a strong tendency to become insoluble during nodule homogenization. This confirms the results of Davenport ${ }^{10}$, who could find only insoluble hemoglobin in actinorhizal nodules.

\section{Concentration of total and CO-reactive heme}

The Soret absorption band for the CO-bound heme in our extracts had a peak at 416 to $420 \mathrm{~nm}$. This is consistent with the properties of a hemoglobin and is evidence against certain of the other hemoproteins that are $\mathrm{CO}$ reactive ${ }^{1,17}$. Cytochrome $\mathrm{P}-450$, whose $\mathrm{CO}$ complex has a peak at $450 \mathrm{~nm}$ is ruled out. Likewise, cytochrome $a_{3}$ is probably not involved, since it is not readily solubilized and its $C O$ peak is at $430 \mathrm{~nm}$. However, there are other CO-reactive hemoproteins that might be present in our extracts. Horseradish peroxidase has an absorption peak at $423 \mathrm{~nm}$, while cytochrome o has a peak at about $416-418 \mathrm{~nm}^{9}$. Thus the absorption maximum at 416 to $420 \mathrm{~nm}$ in our extracts is consistent with the presence of a hemoglobin, but does not rule out certain other CO-reactive hemoproteins. 
The concentrations of total and CO-reactive heme that we found in nodules of Lupinus and Casuarina (Table 1) were comparable to the results of other investigators ${ }^{3,10,11,12}$. This further confirms that actinorhizal nodules such as Casuarina may have hemoglobin contents that approach those found in legume nodules. However, Myrica gale was the only other actinorhizal plant where we found this to be true. In Comptonia, Alnus, and Ceanothus, the concentrations of CO-reactive heme were 5 to 8 times lower than for Casuarina. In Datisca we found no CO-reactive heme at all. Except for Comptonia, these low heme concentrations were accompanied by high nitrogenase (acetylene reduction) activities. Thus there was no indication that the low heme contents were due to a defective symbiosis or other abnormal condition.

In work reported previously ${ }^{28}$, we found much lower concentrations of CO-reactive heme, even though the concentrations of total heme were about the same as reported in Table 1 . The reason is that these earlier extractions were done in the absence of $\mathrm{CO}$. Following the method of Appleby ${ }^{3}$, we modified our procedure and now extract in the presence of $\mathrm{CO}$. We find that the absorption bands of the CO-containing extracts are quite stable when the extract is aerated, whereas the absorption bands of CO-free extracts are rapidly lost.

Because we found evidence for hemoglobins in unrelated genera of actinorhizal nodules, it seemed possible that hemoglobins might be found outside of root nodules. We first examined roots of Ceanothus from which all nodules were removed and found a low but measurable concentration of CO-reactive hemoprotein (Table 1). We found similar results in the roots of all non-nodulating plants examined: Ulmus americana, Acer saccharinum, Helianthus annuus, Triticum aestivum, and Zea mays. Zea mays is the only non-nodulating plant included in Table 1 , since total heme was determined only for this species. As can be seen, CO-reactive heme is responsible for a substantial fraction of total heme in Zea mays.

\section{Difference spectra}

Depending on the material being examined, substances other than CO-reactive hemoproteins absorbed light in the 400 to $650 \mathrm{~nm}$ wavelength range, and distorted the absorption bands. Thus difference spectra were used to compare CO-reactive hemoproteins from various plant sources. In the case of Ceanothus americanus (Fig. 3), the difference spectra clearly showed the presence of a CO-reactive hemoprotein, whereas in extracts and in spectra of nodule slices ${ }^{26}$ the absorption bands are partially obscured by other substances.

The absorption maxima and minima for the difference spectra of plus $\mathrm{CO}$ minus dithionite reduced extracts were similar for all nodules and 


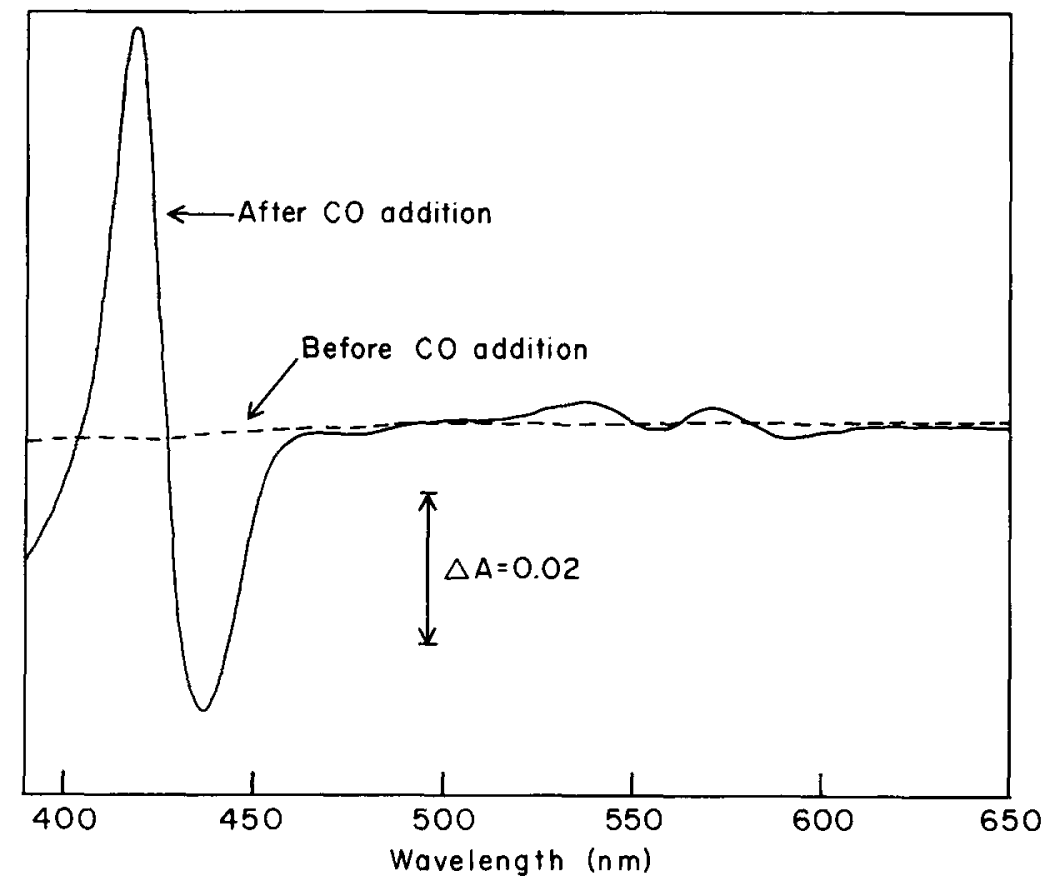

Fig. 3. Difference spectrum of a CO-equilibrated extract from Ceanothus minus a dithionite reduced extract.

roots (Table 2). The wavelengths are consistent with those of a hemoglobin ${ }^{1,17}$, but as discussed above, they could be due at least in part to some other CO-reactive hemoprotein. Whatever the identity of the CO-reactive heme, it has three similarities in all nodules and roots examined: 1 . It is soluble in $1 \%$ Triton X-100 or $5 \%$ soluble PVP. 2 . It makes up a substantial fraction of total heme. 3 . The plus and minus $\mathrm{CO}$ difference spectra are consistent with those of a hemoglobin.

The question of whether the CO-reactive heme is partly or entirely a hemoglobin is best pursued using the purified protein. This has been done for the root nodules of Casuarina glauca, and the protein extracted has all the properties of a hemoglobin, including ligand binding, mole-

Table 2. Difference spectra of hemoprotein extracts ( $\mathrm{CO}$ minus dithionite reduced). The wavelengths of maximum difference are given (nm)

\begin{tabular}{llllll}
\hline Species & + & - & + & - & + \\
\hline Casuarina cunninghamiana & 420 & 437 & 537 & 557 & 572 \\
Myrica gale & 416 & 433 & 532 & 553 & 568 \\
Alnus rubra & 419 & 436 & 536 & 555 & 571 \\
Ceanothus americanus & 419 & 437 & 538 & 557 & 571 \\
C. americanus - roots only & 418 & 437 & - & - & - \\
Zea mays - roots & 419 & 438 & 534 & 555 & 570 \\
\hline
\end{tabular}


Table 3. Effect of $\mathrm{pO}_{2}$ on nodule weight and heme content (mean $\pm \mathrm{SE}, \mathrm{n}=3$ to 6 )

\begin{tabular}{|c|c|c|c|c|}
\hline & \multirow[t]{2}{*}{$\frac{\mathrm{pO}_{2}}{\mathrm{kPa}}$} & $\begin{array}{l}\text { Total } \\
\text { heme }\end{array}$ & $\begin{array}{l}\text { CO-reactive } \\
\text { heme }\end{array}$ & \multirow{2}{*}{$\begin{array}{l}\begin{array}{l}\text { Nodule } \\
\text { fresh wt }\end{array} \\
\text { mg/plant }\end{array}$} \\
\hline & & \multicolumn{2}{|c|}{ nmol g ${ }^{-1}$ (fresh wt) } & \\
\hline \multirow[t]{2}{*}{ Myrica gale } & 5 & $99.2 \pm 3.5$ & $60.7 \pm 4.6$ & $88 \pm 7$ \\
\hline & 20 & $108 \pm 6$ & $70.7 \pm 5.2$ & $192 \pm 24$ \\
\hline \multirow[t]{2}{*}{ Alnus rubra } & 5 & $22.0 \pm 0.8$ & $8.6 \pm 0.4$ & $94 \pm 18$ \\
\hline & 20 & $23.7 \pm 0.9$ & $14.1 \pm 0.6$ & $260 \pm 42$ \\
\hline
\end{tabular}

cular weight, and amino acid sequence ${ }^{12,15}$. Other evidence comes from the absorption spectra of slices of nodules of Myrica gale, Comptonia peregrina, and Alnus rubra ${ }^{26}$. These display the absorption bands of oxyhemoglobin when taken in an atmosphere of $\mathrm{O}_{2}$, while the bands disappear when $\mathrm{N}_{2}$ is substituted for $\mathrm{O}_{2}$. In spite of this evedence, the identity of the heme found in the present study must be considered an open question until further studies are completed.

\section{Possible functions of hemoglobin in actinorhizal nodules}

Much higher concentrations of presumed hemoglobin were found in the nodules of Myrica and Casuarina than in other actinorhizal nodules. Since both of these genera often grow in wet soils, where the oxygen concentration may be reduced ${ }^{25,26}$, we hypothesized that hemoglobin might be serving to facilitate oxygen transport at low oxygen concentrations. Such a function would be similar to the function of leghemoglobin in transporting oxygen at the low oxygen concentrations that prevail within the diffusion barrier of legume nodules ${ }^{2,27}$. An increase in hemoglobin concentration caused by reduced oxygen concentration in the root environment would support this hypothesis. We examined Alnus as well as Myrica, since it also grows in relatively wet soils.

Our results provide no support for the measured heme being involved in an adaptation to reduced partial pressures of $\mathrm{O}_{2}\left(\mathrm{pO}_{2}\right)$. As found by others ${ }^{6.16 .25}$, reduced $\mathrm{pO}_{2}$ in the root zone caused reduced plant growth (results not shown) and reduced nodule weight (Table 3 ). In spite of this oxygen stress, there was little effect on the concentration of total and CO-reactive heme.

The nodules of Casuarina are unique among actinorhizal plants in that the endophyte, Frankia, forms no vesticles in the nodule $e^{4,18}$. Studies of Frankia strain HPCcI3, isolated from Casuarina nodules, show that vesicles are necessary for nitrogen fixation when the cultures are grown at atmospheric $\mathrm{pO}_{2}(20 \mathrm{kPa})$, but are absent when the cultures fix nitrogen at 0.1 to $0.3 \mathrm{kPa} \mathrm{pO}_{2}{ }^{18}$. These results suggest that the $\mathrm{pO}_{2}$ within Casuarina nodules may be low compared to other actinorhizal nodules. A possible cause is the suberization or lignification of the walls of 
Table 4. Evidence for the suberization of the wall of infected cells in selected actinorhizal plants

\begin{tabular}{llll}
\hline Species & \multicolumn{4}{l}{ Test result for lignin-suberin } \\
\cline { 2 - 4 } & Chromic acid & Phloroglucinol & Autofluorescence \\
\hline Casuarina cunninghamiana & ++ & + & ++ \\
Myrica gale & + & + & + \\
Comptonia peregrina & + & + & + \\
Alnus rubra & - & - & - \\
Ceanothus americanus & - & - & - \\
Datisca glomerata & - & - & - \\
\hline
\end{tabular}

infected host cells in Casuarina, which could restrict oxygen diffusion into these cells ${ }^{4}$. If so, the hemoglobin in Casuarina nodules might function to facilitate oxygen transport in a zone of low $\mathrm{pO}_{2}$, as does leghemoglobin in legume nodules.

We decided to investigate the relationship between heme content, suberization, and lignification in the six actinorhizal genera where we measured heme concentration. By comparing Tables 1 and 4 one can see that there is a correlation between the presence of suberization and lignification and elevated heme concentration, except in the case of Comptonia peregrina. Comptonia is closely related to Myrica and we found identical results in the two species when testing for suberin and lignin. However the hemoglobin concentration was much lower in Comptonia, and was similar to that in Alnus, which lacks suberin and lignin. It is possible that these particular nodules of Comptonia were not fully effective, as suggested by their relatively low acetylene reduction rates (Table 1). Overall the data support a relationship between elevated heme content and the presence of suberized and lignified walls, but more information is needed to elucidate the nature of this relationship.

Since hemoglobins have a high affinity for $\mathrm{CO}$, it seemed possible that nodules with little or no hemoglobin might be less sensitive to inhibition by $\mathrm{CO}$ than those with high concentrations of hemoglobin. If so, this might be used to study the function of the hemoglobin. As can be seen by comparing Tables 1 and 5, there was no correlation between hemoglobin content and the inhibition of acetylene reduction by $\mathrm{CO}$. The

Table 5. Inhibition of acetylene reduction in actinorhizal and legume nodules by $0.33 \mathrm{kPa}$ of $\mathrm{CO}$ (mean $\pm \mathrm{SE}, \mathrm{n}=3$ to 6 )

\begin{tabular}{ll}
\hline Species & Inhibition(\%) \\
\hline Alnus rubra & $43 \pm 4$ \\
Casuarina cunninghamiana & $54 \pm 1$ \\
Datisca glomerata & $60 \pm 7$ \\
Myrica gale & $62 \pm 4$ \\
Ceanothus americanus & $95 \pm 2$ \\
Lupinus albus & $90 \pm 2$ \\
Pisum sativum & $82 \pm 3$ \\
\hline
\end{tabular}


inhibition observed could have been due to the effect of $\mathrm{CO}$ on a cytochrome oxidase, hemoglobin, or nitrogenase itself ${ }^{17,22}$. Using ${ }^{15} \mathrm{~N}$, Bond found comparable results for inhibition by $\mathrm{CO}$ in nodules of Alnus, Myrica, and Pisum ${ }^{7}$.

\section{Conclusions}

Our results establish that there are high concentrations of total and CO-reactive heme in the nodules of Myrica gale and Casuarina cunninghamiana. However, the concentrations of heme in other actinorhizal genera were about 5 to 8 times lower, with no significant differences in acetylene reduction rates by nodules with high and low heme contents. Moreover, Datisca nodules had typical acetylene reduction rates, but no detectable heme that was extractable and CO-reactive. We thus conclude that high heme contents are not essential for nitrogen fixation in actinorhizal nodules.

The CO-reactive heme in Casuarina cunninghamiana is probably a hemoglobin, since large amounts of a hemoglobin have been purified from the nodules of Casuarina glauca ${ }^{12}$. It is now of great interest to purify and characterize the CO-reactive heme extracted from actinorhizal plants such as Alnus rubra and non-nodulating plants such as Zea mays. If this proves to be a hemoglobin, it would suggest that hemoglobins have some relatively general function in plants.

Our initial investigations into the function of the CO-reactive heme in actinorhizal nodules have been inconclusive. There is a possible relationship with suberization of the cell wall of the infected host cells, but this needs more study. No correlation was observed between heme content and either root zone $\mathrm{pO}_{2}$ or the sensitivity of nitrogenase activity to $\mathrm{CO}$ inhibition.

The simplest hypothesis is that the CO-reactive heme measured in Table 1 is a hemoglobin and functions in facilitating oxygen transport in tissues where the $\mathrm{pO}_{2}$ is low. This is the most likely function of the lethemoglobin present in legume nodules ${ }^{2}$. Variations in the concentration of hemoglobin in nodules and roots might be due to variations in the intensity of respiration and the resistance to oxygen diffusion to the sites of respiration.

\footnotetext{
Acknowledgements We thank Linda Krywy for expert technical assistance, Mary Lechevalier for providing Frankia strain LLR 161101 , John Torrey for providing some of the seed and Frankia strains used, Larry Winship for seeds of Datisca, Christa Schwintzer for helpful comments on the manuscript, and Cyril Appleby, Tony Fleming, Jonathan Wittenberg, Beth Mullin, Douglas Johnson and Ian Sussex for helpful discussions and data in advance of publication. This work was supported by US National Science Foundation Grant No. DMB-8315415.
} 


\section{References}

1 Appleby C A 1969 Electron transport systems of Rhizobium japonicum. II. Rhizobium hemoglobin, cytochromes and oxidases in free-living (cultured) cells. Biochim. Biophys. Acta 172, 88-105.

2 Appleby C A 1984 Leghemoglobin and Rhizobium respiration. Annu.Rev. Plant Physiol. $35,443-478$.

3 Appleby C A, Tjepkema J D and Trinick M J 1983 Hemoglobin in a nonleguminous plant, Parasponia: possible genetic origin and function in nitrogen fixation. Science 220, 951-953.

4 Berg R H 1983 Preliminary evidence for the involvement of suberization in infection of Casuarina. Can. J. Bot. 61, 2910-2918.

5 Berry A and Torrey J G 1979 Isolation and characterization in vivo and in vitro of an actinomycetous endophyte from Alnus rubra Bong. In Symbiotic Nitrogen Fixation in the Management of Temperate Forests. Eds. J C Gordon, C T Wheeler and D A Perry. pp 69-83. Oregon State University, Corvallis, OR.

6 Bond G 1952 Some features of root growth in nodulated plants of Myrica gale L. Ann. Bot. $16,467-475$.

7 Bond G 1960 Inhibition of nitrogen fixation in non-legume root nodules by hydrogen and carbon monoxide. J. Exp Bot. 11, 91-97.

8 Burris R H 1974 Methodology. In The Biology of Nitrogen Fixation. Ed. A. Quispel. pp 9-33. North-Holland Publishing Co., Amsterdam.

9 Castor L N and Chance B 1959 Photochemical determinations of the oxidases of bacteria. J. Biol. Chem. 234, 1587-1592.

10 Davenport H E 1960 Haemoglobin in the root nodules of Casuarina cunninghamiana. Nature $186,653-654$.

11 Egle K and Munding H 1951 Über den Gehalt an Häminkörpen in den Wurzelknöllchen von Nicht-Leguminosen. Naturwiss. 38, 548-549.

12 Fleming A I, Wittenberg B A, Wittenberg J B and Appleby C A 1985 Hemoglobin in the root nodules of the actinorhizal genus Casuarina. Proc. Aust. Biochem. Soc. 17, 24 (Abstr.).

13 Hardy R W F, Burns R C and Holsten R D 1973 Application of the acetylene reduction assay for measurement of nitrogen fixation. Soil Biol. Biochem. 5, 47-81.

14 Hattori J and Johnson D A 1985 The detection of leghemoglobin-like sequence in legumes and non-legumes. Plant Molec. Biol. 4, 285-292.

15 Kortt, A A, Burns J E, Inglis A S, Appleby C A, Trinick M J and Fleming A I 1985 Hemoglobins from the nitrogen-fixing root nodules of non-legumes and their relationship to the legume hemoglobins. Proc. Aust. Biochem. Soc. 17, 43 (Abstr.).

16 MacConnell J T 1959 The oxygen factor in the development and function of the root nodules of alder. Ann. Bot. 23, 261-268.

17 Mahler H R and Cordes E H 1966 Biological Chemistry. Harper and Row, New York, 872 p.

18 Murry $\mathrm{M}$ A, Zhongze $\mathrm{Z}$ and Torrey $\mathrm{J} \mathrm{G} 1985$ Effect of $\mathrm{O}_{2}$ on vesicle formation, acetylene reduction and $\mathrm{O}_{2}$-uptake kinetics in Frankia sp. HFPCcl3 isolated from Casuarina cunninghamiana. Can. J. Microbiol. 31, 804-809.

19 Paul K G, Theorell H and Åkeson $\AA 1953$ The molar light absorption of pyridine ferroprotoporphyrin (pyridine haemochromogen). Acta Chem. Scand. 7,1284-1287.

20 Roberts M P, Jafar S and Mullin B C 1985 Leghemoglobin-like sequences in the DNA of four actinorhizal plants. Plant Molec. Biol. 5, 333-337.

21 Roberts M P, Jafar S and Mullin B C 1985 Leghemoglobin-like sequences in the DNA of non-leguminous plants. First International Congress of Plant Molecular Biology, Savannah, Georgia, Abstract No. OR-05-02.

22 Rivera-Ortiz J M and Burris R H 1975 Interactions among substrates and inhibitors of nitrogenase. J. Bacteriol. 123, 537-545.

23 Schulman A H 1986 The Detection of DNA sequences Similar to Leghemoglobin Genes in the Genomes of Non-Leguminous Plants. Ph.D. Dissertation, Yale University.

24 Schulman A H and Sussex I M 1985 Detection of DNA sequences from non-legumes with homology to soybean leghemoglobin genes. First International Congress of Plant Molecular Biology, Savannah, Georgia, Abstract No. PO-2-104. 
25 Schwintzer C R 1985 Effect of spring flooding on endophyte differentiation, nitrogenase activity, and shoot growth in Myrica gale. Plant and Soil 87, 109-124.

26 Tjepkema J D 1983 Hemoglobins in the nitrogen-fixing root nodules of actinorhizal plants. Can. J. Bot. 61, 2924-2929.

27 Tjepkema J D 1984 Oxygen, hemoglobins, and energy usage in actinorhizal nodules. In Advances in Nitrogen Fixation Research. Eds. C Veeger and W E Newton. pp 467-473. Martinus Nijhoff, The Haugue.

28 Tjepkema J D and Murry M A 1985 Heme content and diffusion limitation of respiration and nitrogenase activity in nodules of Casuarina cunninghamiana. In Nitrogen Fixation Research Progress. Eds. H J Evans, P J Bottomley and W E Newton, p 370. Nijhoff, Dordrecht.

29 Tjepkema J D, Schwintzer C R and Benson D R 1986 Physiology of actinorhizal nodules. Annu.Rev. Plant Physiol. 37, 209-232.

30 Wakabayashi S, Matsubara H and Webster D A 1986 Primary Sequence of a dimeric bacterial haemoglobin from Vitreoscilla. Nature $322,481-483$.

31 Winship L J and Tjepkema J D 1983 Simultaneous measurement of acetylene reduction and respiratory gas exchange of attached root nodules. Plant Physiol. 70, 361-365.

32 Zhang Z, Lopez M F and Torrey J G 1984 A comparison of cultural characteristics and infectivity of Frankia isolates from root nodules of Casuarina species. Plant and Soil 78, 79-90. 